\title{
Bioluminescence: the First 3000 Years (Review)
}

\author{
John Lee* \\ Department of Biochemistry and Molecular Biology, \\ University of Georgia, Athens GA 30602 USA $^{I}$
}

Received 26.08.2008, received in revised form 2.09.2008, accepted 9.09.2008

Bioluminescence is defined as the emission of light from a living organism that performs some biological function. Bioluminescence is one of the oldest fields of scientific study, dating from the first written records of the ancient Greeks. This article describes the many investigations of animal luminescence up to the end of the $19^{\text {th }}$ Century. Many facets of this field are easily accessible for investigation without need for advanced technology and so, within the History of Science, investigations of bioluminescence played a significant role in the establishment of the scientific method, and also were among the many visual phenomena to be accounted for in developing a theory of light.

Key words: Pliny, Boyle, phosphor, firefly, glowworm, oxygen

We live in an age of illumination. Before the mid-1800's, even in the more developed industrial countries, only a small minority of people dwelled in townships, where there might be some form of lighting to counter the nighttime darkness. For the rest of humanity, the night generally brought complete blackness, modulated only by star-light or the moon. Inside a dwelling there may be light from candles or a fire but a person venturing outside, and after about the 20 minutes for attaining dark-adapted vision, would likely encounter one of the common terrestrial forms of animal light, insects or luminous mushrooms. One can readily believe that some of these for instance the pale glow of a rotting $\log$, due to a luminous fungal infection, could be a frightening experience, and may be an origin of belief in haunting by ghosts or spirits. Glowing mushrooms would also be common and perhaps not so frightening and also, according to some accounts, many primitive tribes have used live fireflies as forms of decoration or for illumination.

In temperate and tropical climates, the common firefly is the most frequently encountered example of light produced by live organisms. This property of cold light emission found in a variety of living creatures, is called «Bioluminescence», and is one of the oldest subjects of scientific study. So-called «living light» is widely distributed in the biosphere and in the ocean the majority of species exhibit bioluminescence. Although bioluminescence is more rare on land, the terrestrial environment is where this phenomenon was more frequently reported. Light emanating from living creatures was one of the many instances of light emission, along with that from the Sun, Moon, and stars, oil lamps, fire, and so on, that in ancient times, had to be folded into an explanation of the nature of light itself.

\footnotetext{
* Corresponding author E-mail address: jlee@uga.edu
}

(C) Siberian Federal University. All rights reserved 


\section{Antiquity}

There are no written records of observations of bioluminescence to be found more than 3000 years BP (Before the Present). Although humans were settling into agricultural communities 10,000 years BP in China and Mesopotamia, «The Fertile Crescent», written descriptions of observations of luminescence only appear much later. Due to the cumbersome technology of writing, clay tablets, etc., only information vital to the survival of the people would have been essential to preserve, such as the location on the immediate horizon of rising and setting of the Sun for prediction of seasons, etc. Therefore, from far antiquity, mention of animal light comes to us only in the form of poetry and folk songs. Some poetry from China, refers to the «night travelers», apparently we guess, the fireflies, known to be very common in South China. There are some myths about the origin of fire being from the «burning of the sea», ocean «phosphorescence», which we now know to be due to bioluminescent plankton or dinoflagellates.

Ancient Greece in the $5^{\text {th }}$ Century BCE (Before the Christian Era) is considered to be the birth-place of scientific thought. Anaximander (647-611 BCE), called the «the first scientist», promulgated the idea that natural events obeyed certain laws, in the same way that laws regulated individual behaviors in society, and made observations and proposed explanations of some natural phenomena. Empedocles (490-430 BCE) considered that things were made of «stuff», a forerunner of an atomistic theory. He postulated that four elements made up all matter: fire, earth, air, and water. Light he proposed, was due to emanations from the eye based on observations among others, of perception of light flashes on pressing the eyeball. His theory of vision persisted for many centuries although it was disputed by Euclid (Optics, 300 BCE) from his observations that light traveled in straight lines, the laws of reflection, etc.

In this period, written reports of luminescent organisms remained fragmentary up till the time of Aristotle (384-322 BCE). Aristotle was the first to record detailed observations and to recognize the self-luminosity of bioluminescent organisms and the property that it was not accompanied by heat, contrasting with the light from a candle flame. Aristotle wrote about the luminosity of dead fish and flesh, now known to be due to infection by bioluminescent bacteria, the light seen on disturbing sea-water by striking it with a rod (as mentioned above, mostly from the dinoflagellates), and of fireflies and glowworms.

The first specific and complete record of bioluminescent organisms in these times, was by Pliny the Elder (23-79 CE). In his Naturalis Historia, there are quite detailed descriptions of many bioluminescent animals: the glowworm and fireflies, the luminous mollusc (Pholas dactylus) (a Roman delicasy), the purple jellyfish (Pelagia noctiluca) still common in the Mediterranean, the lantern fish, luminous mushrooms, and glowing wood (Fig. 1, 2). Pliny also wrote that there were

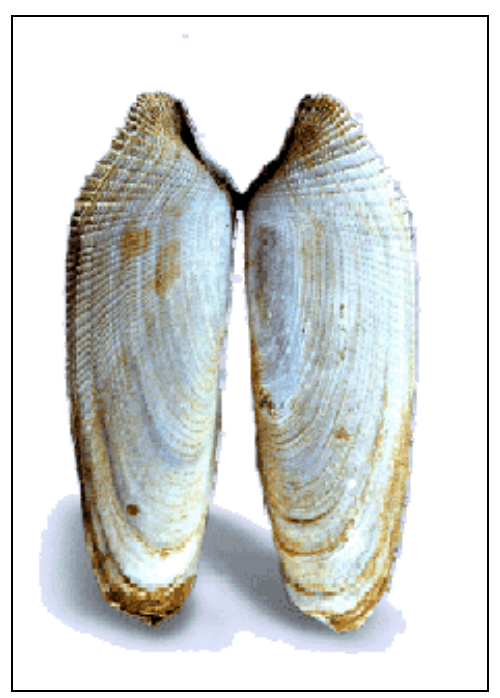

Fig. 1. The bioluminescent mollusc Pholas dactylis (a Roman delicasy). It is commonly known as a «piddock» 

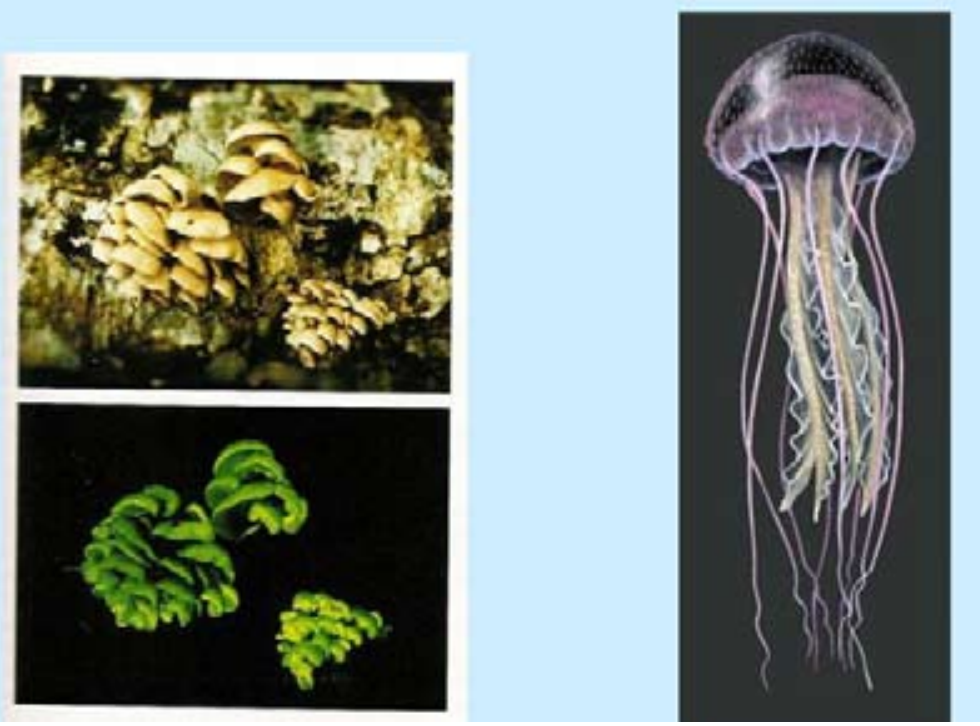

Fig. 2. Pliny the Elder (23-79 CE) in his Historia Naturalis, described the luminous mushrooms and «Medusa», probably Pelagia, a purple jellyfish

reports of luminous birds in the Black Forest of Germany but added that this was just hearsay and unfounded rumor. Nevertheless, the belief that such bioluminescent birds existed, continued for more than a thousand years showing the persistence of unsubstantiated rumor without independent verification.

\section{The Middle Ages to the $16^{\text {th }}$ Century}

This period spans a millennium, almost from the fall of the Roman Empire (500 CE) to the Renaissance in Europe. Although the Dark Ages descended on Europe over the first part of this period, scientific progress along with mathematics and engineering, continued in Arabia, India and China. With the increase in trade and ocean voyages, there are many reports in literature of this time, of the ocean «phosphorescence». Also there are descriptions of the Chinese «candle fly», an insect possibly similar to the «click beetle» (Pyrophorus) from the Caribbean. Otherwise, very little new observations of luminescence were reported or explained until around the $12^{\text {th }}$ Century, with the writings of Albertus Magnus (1206-1280 CE), a German monk and regarded as «the first naturalist». After the invention of the printing press, his work was published in 1478 as a book De Animalibus. Magnus described and cataloged many luminous species but not much in addition to Pliny's list. He also stated that it was possible to make extracts of fireflies, «Liquor lucidus» producing a permanent luminescence. Again, this was a myth, another rumor perpetuated without independent experimental verification. The luminous birds also received mention again as factual.

The next few hundred years, the period of the Renaissance, saw a revival of learning in Europe, and also increase in maritime exploration and trade. By the end of the $15^{\text {th }}$ Century, learning and scholarship were no longer confined to religious organizations but taken over increasingly by naturalists, usually trained as physicians, and by explorers. Voyagers brought back reports of «burning seas», probably the phenomena now called «milky seas», and still not understood. Christopher Columbus (1492), referred to mysterious lights in the sea occurring just before he reached San Salvador, and this was probably due to a marine worm, (Odontosyllis), known to 

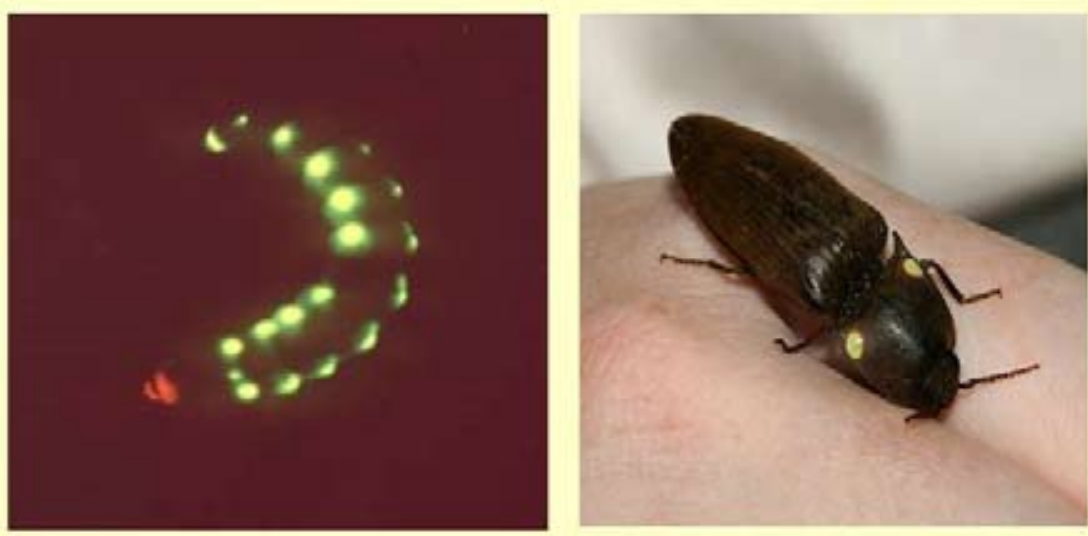

Fig. 3. Bioluminescent insects from the Caribbean. Left. Railroad worm (Phengodidae: Phrixotrix) photo: V. Viviani. Right. Click beetle (Elateridae: Pyrophorus)

inhabit these Caribbean waters. Oviedo (1478$1557)$ in Spain, the official chronicler of Indian affairs, visited many parts of the New World and published extensively on natural history. He identified the elaterid beetle (Pyrophorus), bioluminescent caterpillars and the railroad worm (Phenogoides) (Fig. 3). Tropical fireflies in the East Indies were also seen and described by Sir Frances Drake (1540-1596).

Conrad Gestner (1516-1565), Professor of Natural History and Medicine in Zurich, is credited with writing the first book devoted to luminescence, De Lunariis, covering bioluminescent animals and plants, as well as luminous stones. This book was a collection of observations going back to the ancients, including several marine species, the fireflies and caterpillars, and luminous wood. Gestner was definitely skeptical about the existence of self-luminous plants, recognizing the origin as by reflection, but not about the luminous birds in Germany. He was in much company in believing in these mythical creatures and also in the $15^{\text {th }}$ Century, most scholars still believed in light rays emanating from the eye, from the apparent evidence of the glowing of cats' eyes in reflected light. For scholars, the $16^{\text {th }}$ Century was a period of collecting and reporting of natural phenomena, with little attempt at explanation. The value of «experimentation» was not yet ready to be realized.

We might ponder here, the question of why the scientific method we are familiar with today, took so long to be born, when it was incipient in the works of Aristotle and Pliny. The Middle Ages in Europe were a period of superstition and belief in magic. All learning was restricted to members of the Church and many studies of natural phenomena like luminescence, were of an «applied» nature, to maintain belief in the spirits or for producing magic nostrums. It was not until learning «escaped» from religious dogma, and passed into the hands of physicians and the great explorers, that more objective and detailed observations could ensue. And also, it should be emphasized, profitable commercial transactions would demand reliable and predictive knowledge that can only be obtained from a scientific methodology.

\section{The $17^{\text {th }}$ Century: The Science Revolution}

There were three intellectual movements in the $17^{\text {th }}$ Century which qualify this period as one of «Science Revolution». The first was promulgated by the philosophers Sir Francis Bacon (1561-1626) in England, and in France 
by Renee Descartes (1596-1650); their ideas laid the foundations of Science itself. The second movement resulted from the expanding intellectual interest in luminescence phenomena, both animal light and inorganic luminescence, that from phosphorescent stones of various types. These many new discoveries called out for understanding. The third movement was the idea of the importance of experimental observation, the most prominent in this belief being Robert Boyle (1627-1691), who announced that «Experiment is the interrogation of Nature».

Sir Francis Bacon is generally credited with establishing the "scientific method», how to determine true knowledge by the process of Induction. His revolutionary proposal (Cogitata et Visa, 1607; Novum Organum, 1620) was that true knowledge is obtained by carefully observed and verifiable, particulars, or instances. After collecting a sufficient number of such observations, one would propose a modest generalization or axiom, from which a direction for collecting more observations relevant to this axiom, would be conceived. Bacon emphasized that it was as important to find refutations of the axiom as instances of support, because the former would suggest that a change of direction in the search for a better axiom was needed. Bacon's system demanded a continuous process of collecting observations and induction of axioms, then deduction for prediction of where relevant observations should be pursued, until some overall general, but not final, axiom could be proposed.

Bacon's system dominated the methodology of biological sciences for more than two hundred years, the collection and classification of instances. Indeed, it was admitted by Darwin that On the Origin of Species (1859) was based on the Baconian system. Although Darwin did collect numerous instances of species and interrelationships, he broke from the Baconian system by theorizing a mechanism, namely evolution by transmutation and natural selection. Bioluminescence was indicated by Darwin, as one of the difficulties in his theory, in that how it would evolve in gradual stages.

In subsequent times, Darwin's theory has evolved into a grand foundation for all of Biology, in other words, corresponding to the doctrine espoused by Descartes for the essentiality in Science of a Grand Theory. It is also interesting that in modern times, the idea popularized by Karl Popper that an hypothesis becomes more useful if it suggests ways it can be falsified, has its origin in Bacon's system. However, Bacon did not consider hypothesis, that is imagination, to be so essential, although nowadays it is considered the lynchpin of scientific progress.

The French school of thought was initiated by Renee Descartes. Bacon recognized that the Sciences lacked a theory of light but he never got to address this special problem. The system of Descartes was in contrast to Bacon's, one of deduction, where one starts from a general law or (grand) foundational principle, to arrive at a particular case. Descartes proposed a theory of light, first he dismissed the idea that space could be a vacuum, instead he imagined it to be a plenum of contiguous particles, all jostling and crowded together. Thus he deduced that light originated from the friction of the particles rubbing together and was transmitted by one particle pushing against the next. In Principia Philosophia (1644) he presented explanations for the various forms of luminescence, such as light from sea-water arising on vigorous disturbance by the oars of a boat, or the bioluminescence of fish as due to particles of salt penetrating the pores. Descartes' attention to luminescent phenomena was only a small part of his work overall but many other bioluminescence systems were elaborated on by workers of the French school. Generally, socalled Cartesian principles, from that time formed 
the foundation of mathematical physics and it is in the physical sciences that the general laws of Nature were most strongly formulated.

By the late $17^{\text {th }}$ Century the theory of light was modified and divided into opposing views, the wave theory of Hooke and Huygens, and that light consisted of corpuscles, the idea more associated with Newton (1642-1727) than Descartes. Due mainly to the dominant reputation of Newton, the corpuscular theory remained unchallenged until almost 150 years later, when it was clearly incompatible with the diffraction experiments of Young and the work of Fresnel.

Kircher (1602-1680), a German Jesuit priest, was the first in this period to produce a book with a substantial treatment of luminescence. In addition to compiling all reports going back to Aristotle, applying the Baconian system, Kircher collected and tabulated many observations of «light inherent in animals». In one example, he noted in fireflies that the light would dim on handling the insect, then reappear if left alone. Many of the insects placed together would display «ostentatiously». Kircher then conjectured the function (the axiom) that the light was in order to be seen, and extended this idea to the function of bioluminescence in the fish in the darkness of the ocean, that it was similar to the fireflies, for communication. Kircher's suggestions we now know, to be essentially correct. He continued even to do experiments, showing how the luminescence on some organisms such as the clam Dactylus, could be rubbed off on a stick. By experiment he also showed that the claim of the ability to produce the liquor lucidus, the indefinitely glowing extract from firefly light organs (photophores), was demonstrably false.

The most highly regarded and comprehensive book on luminescence was De Luce Animalium (1647) by Bartholin (1616-1680), a Danish physician. He traveled widely and described in his book all luminescent phenomena known at that time. He proposed that light was present in all things, the shining of a leg of lamb in a marketplace, sparks from rubbing together steels, from hair, clothing, minerals, plants, fish, and so on, some being from bioluminescence, others we now know to be from friction, reflection, or iridescence. Most of Kircher's interpretations we now regard as false. He used all these instances to propose that light was present in all things and constituted a fifth principle of matter, i.e., in addition to the four elements proposed in ancient times, fire, earth, water, and air. Bartholin attempted explanations of the luminescent property, both how it arises in the modern meaning of this term and of the purpose of the light. Much of his explanations are in terms of religious references and becomes meaningless in our present scientific world-view. Nevertheless, the publication of these many observations stimulated much investigative activity of luminescence, yielding a number of monographs and theses in the latter part of the century. Also in this time three new bioluminescent organisms were discovered, a marine worm symbiotic with living oysters, luminous earthworms from the south-east coast of India, and the lantern-fly, Fulgora, in Surinam.

Robert Boyle (1627-1691) was a leading intellectual of the seventeenth century. Being a scholar of his time, he studied and wrote extensively on the subjects of philosophy and theology but ahead of his time, his most prolific and long-lasting interest was in the value of quantitative, systematic, and recorded, experimental observations. $\mathrm{He}$ performed and published the results of so many seminal experiments that he is regarded as the «Father of Modern Chemistry». He was a strong believer in the Baconian approach, collecting and categorizing results both positive and negative, and without intention of formulating any grand theory according to the philosophy of Descartes. 


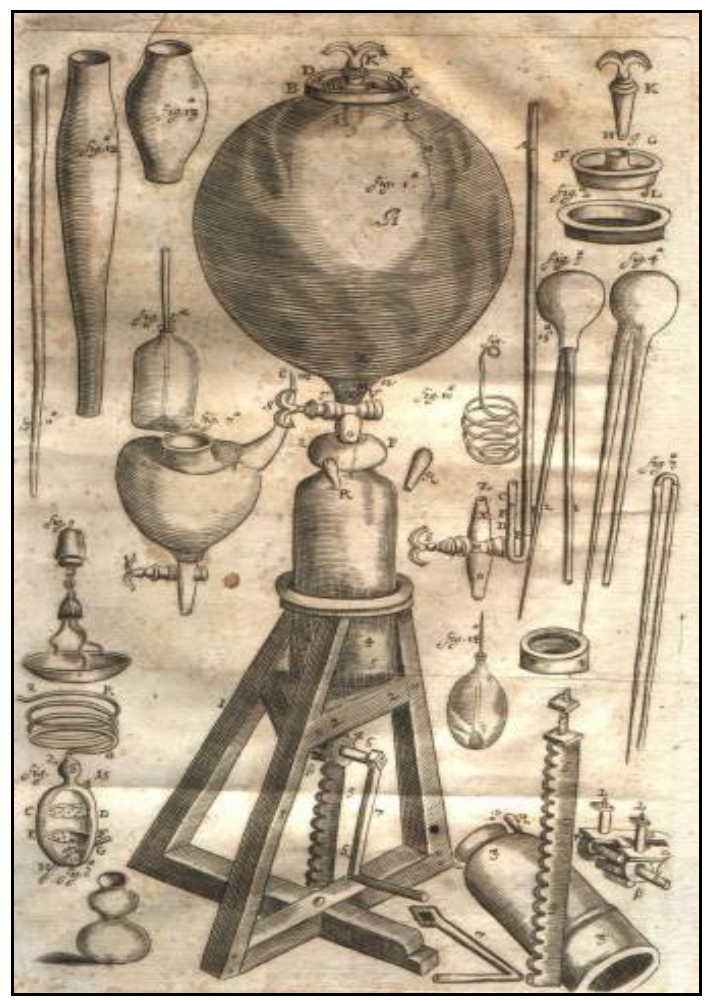

Fig. 4. The air pump constructed by Robert Hooke and Robert Boyle (1667)

Boyle is best known for the experiments establishing «Boyle's Law», the inverse relation of pressure and volume of a gas. Unusual for the time, the observations were published in a table with the quantitative values of the pressures and volumes listed therein.

Boyle was among the founders of the Royal Society (1662). He had a strong interest in a wide range of chemistry and physics problems, one being luminescent phenomena on which he produced many papers, which can be read on-line nowadays in the Proceedings of the Royal Society. Boyle had been aware of the many reports of both inorganic and animal light and had his able assistant Robert Hooke, construct an improved version of the recently invented air pump, for experiments on the properties of air (Fig. 4). Just as Galileo made many discoveries with the newly invented telescope, Boyle utilized «state-of-theart» technology to gain novel results and insight into natural phenomena.
Boyle's observations of the effects of air on various forms of luminescence, we now know to be due to the properties of oxygen, which was not identified as a constituent of air for another 100 years. Hooke's improved apparatus contained a glass chamber, inside of which could be placed objects for observation of the effect of the presence or absence of air. Removal of the air over iron heated to red-hot emission, was found to be without effect, whereas for a candle flame or a glowing coal, the luminescence was extinguished, and did not recover on readmission of the air. Boyle recorded that a live mouse died in the absence and did not recover on readmission of the air, whereas for a piece of shining wood or a glowworm, the light only dimmed and then exuberantly re-emitted the glow on allowing the air to re-enter the test chamber. The presentday explanation is that oxygen is an essential requirement both for the respiration of living creatures and for bioluminescence (Fig. 5). The 


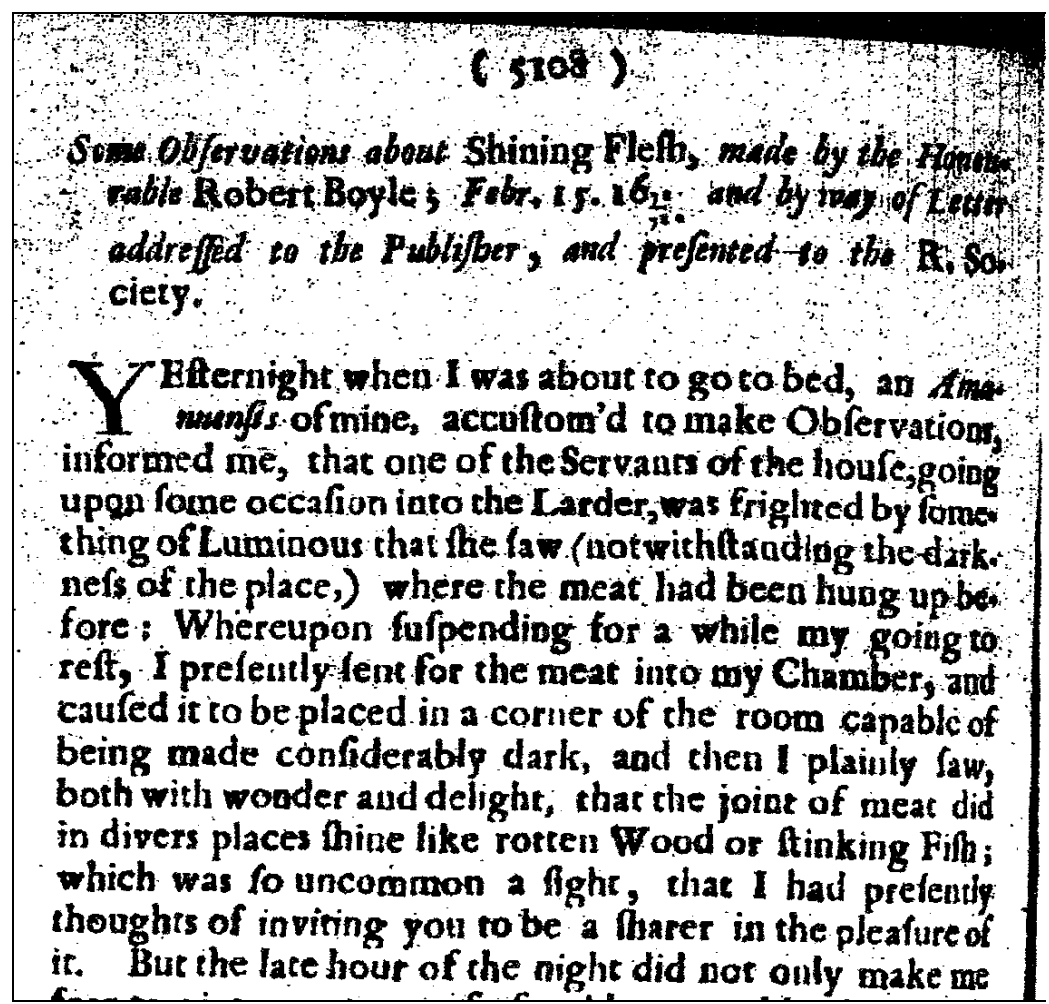

Fig. 5. First page from: R. Boyle. Philosophical Transactions of the Royal Society, London, volume 7, pages 5108$5116(1672)$

light from most bioluminescence systems may only dim and not extinguish, because extremely small amounts of oxygen still support the emission, and when the oxygen is removed for some short period, the reaction precursors build up and produce a burst of reaction to luminescence when the oxygen is added.

The $18^{\text {th }}$ Century: The Age of Experiment

Joseph Priestly in 1772, wrote that «astonishing improvements that have been made...in all branches of real knowledge, in little more than two centuries [since] the expiration of that long period of darkness, cannot help forming the most glorious expectations.» Boyle had shown the power of the experimental approach with his great achievements in many areas of Science. Thus, Science in the $18^{\text {th }}$ Century became highly experimental, particularly with investigations of electricity, heat and light, and also most importantly, in the determination of the composition of air.

The discovery of oxygen, or «dephlogisticated air», as it was called then, is attributed to Priestly in England, Lavoisier in France, and Scheele in Germany. The theory or doctrine, of Phlogiston, was that this was a chemical substance that escaped when a compound was burned, a fireprinciple associated with that substance. Thus when a candle was burned or an animal was left to respire in a closed system, what remained was noxious, «azote» (without life), i.e., nitrogen. The Phlogiston theory was eventually overturned by Lavoisier's measurements of the masses involved in these changes. Interestingly, the theory itself was irrelevant. The fact was that the composition of air remained unchanged whatever the final and correct interpretation.

While not specifically about bioluminescence systems, the discovery of oxygen and ideas about 
the nature of combustion and the associated generation of light emission, led to realization that respiration, combustion and bioluminescence, could be related processes. The air-pump experiments of Boyle were repeated and the results confirmed. Forster in Copenhagen, observed control of the firefly flash on removal or admission of air to the insect. Spallanzi in Italy, carried out careful experiments on the effect of oxygen. He found that removal of the air dimmed the light from luminous wood or a dead bioluminescent squid, but readmission of oxygen caused it to glow brighter, even than before in air. He found the light to disappear under nitrogen, hydrogen, and carbon dioxide («fixed air»). He concluded that bioluminescence was in nature of a slow burning.

Some observations such as these, were quite controversial mainly due to the lack of reliable equipment and other technologies that made it difficult to obtain accurate results. The airpumps leaked and were inefficient, and it was not realized just how small the amounts of oxygen that were needed to optimize the bioluminescence reactions.

In the field of bioluminescence, two other discoveries of significance occurred. One was that the principle responsible for the light emission was dissociable from the living animal; bioluminescence was not a vital process. The luminous material from the clam Pholas, could be scraped out, made into a paste with flour and kept for a year, the light reconstituted on adding water. The luminous material from the jellyfish could be dried, then the light returned on adding water. Therefore, bioluminescence was clearly a reaction occurring in aqueous solution.

The second series of observations concerned the nature of light in the sea. In the latter half of the century with the plethora of luminescent creatures discovered in the top layers of the ocean, the jellyfish and other animals down to the size of crustaceans, there was effort given to microscopic examination of sea-water samples. Copepods were found in abundance and other «sea-worms» and eventually, even «sea-insects» were visible under the primitive microscopes available at that time. It was therefore concluded that the origin of «sea-light» or ocean «phosphorescence», was indeed from «animacules». The true origin as from the dinoflagellates, however, took another 50 years to be definitely established.

\section{The $19^{\text {th }}$ Century: Modern Science}

By the beginning of the $19^{\text {th }}$ Century, the methodology of scientific investigation was well established. Numerous pamphlets and books were being published, scientific societies were growing, and fields of Science were dividing into specialties, Physics, Chemistry, and Biology. Newton's corpuscular theory of light was no longer in favor, following the interference and diffraction experiments of Thomas Young. Light was believed to consist of waves occurring in a space-filling «ether», an idea going back to the «plenum» of Descartes. It was another 100 years before the presence of such an ether was disproven and the particle-wave duality theory of light established. With the availability of technology to make accurate measurements for investigating the nature of light, the attention of physicists turned to physical optics. The study of animal luminescence became the prerogative of the biologists.

For the biologists also, it was again the availability of state-of-the-art improvements of instrumentation that enabled many discoveries. One of these was the microscope with more precise optics giving higher power. Although biologists were all of the opinion that ocean phosphorescence was due to "animacules», these had been too small to be detected. Detection and description of the dinoflagellates was convincingly shown by Macartney (1810) and attributed as the main 


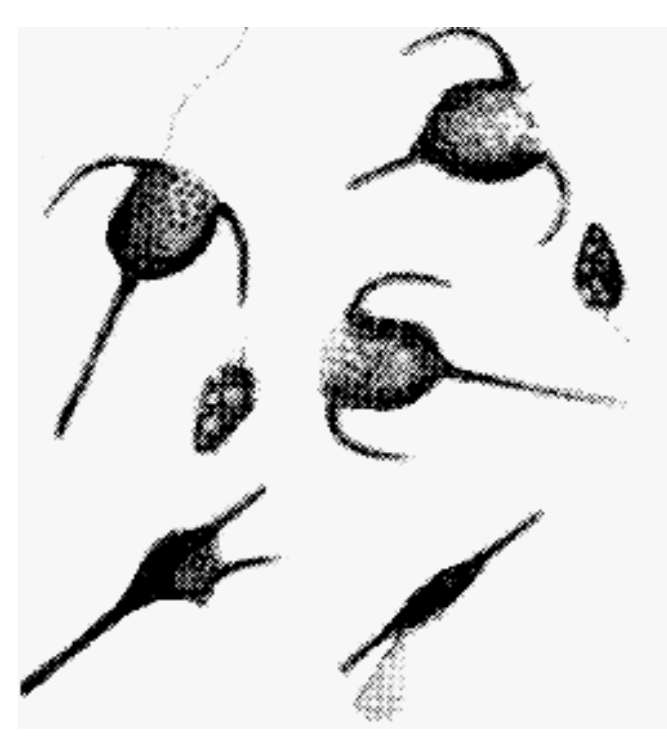

Fig. 6. Drawing of dinoflagellates under the microscope, by Michaelis and Ehrenberg (1830-1840)

source of ocean «phosphorescence» by Michaelis and Ehrenberg (Fig. 6). Macartney observed that the bioluminescence from these dinoflagellates responded to mechanical stimulus, leading to the suggestion that the light emission might have some sort of protection function. Other types of stimuli, e.g., electrical, were also observed from living luminescent specimens, connecting the bioluminescence property as under some sort of muscular control. With recent evidence that the firefly bioluminescence served for communication leading to mating, some purpose for light emission could naturally be extended to the dinoflagellates and other bioluminescent organisms. Microscopic study of the dinoflagellates also revealed the bioluminescence to be localized in discrete particles floating in the cytoplasm; in recent times these have been labeled «scintillons».

At the beginning of the century, both inorganic and animal light emission were believed to arise from the element phosphorus or some form of phosphorus, present in the material or excreted by the organism, because of the similar light emission of phosphorus on exposure to air. This was the origin of the terms phosphor and phosphorescence, the last popularly used for the bioluminescence from sea water, but now having a particular scientific usage referring to a delayed type of fluorescence emission.

With chemical sciences developing rapidly at this time, it was soon realized that the mixtures reacting to give the luminescence outside the organism, were organic in nature. In 1877, the first chemiluminescence reaction was discovered, that from oxidation of an organic substance lophine. This led to a proposal that bioluminescence was some form of chemiluminescence occurring within the animal.

The work of Dubois towards the end of the century, verified this idea completely. Dubois made a paste of the luminescent material from the clam Pholas, and suspended this in cold water producing a glowing solution which he divided into two parts. One part was heated near boiling whereupon the glow was extinguished. After the first part of the cold-water extract ceased glowing, the re-cooled hot-water sample was mixed in and light emission started up again. Dubois also showed that extracts of the clickbeetle Pyrophorus similarly produced light from a hot-water cold-water reaction.

Dubois concluded that the bioluminescence was chemical in nature and the heat stable part was probably an organic molecule, which he named «luciferine»." The active ingredient in the first part of the extract had to be kept cool for an effective reaction, in other words it was heat labile and, with the discovery of «enzymes» from advances in fermentation research going on at this same time, Dubois thought that the cold water extract could also be an enzyme, and labeled it «luciferase». These names have persisted up to this present time, except with the «e» dropped from «luciferine». It is also now realized that luciferin and luciferase are generic names, being usually specific to a bioluminescent system, i.e., the luciferin and luciferase for firefly 
are completely different molecular structures from those for the jellyfish, different again from dinoflagellates, earthworms, etc.

Another major advance in the $19^{\text {th }}$ Century was the improved technology of ocean-going vessels. This increased the ability for world exploration and particularly for well-outfitted scientific cruises, probably the most famous being Darwin's voyages on the Beagle (1831-36) and the expeditions (1872-76) of the HMS Challenger. Whereas the majority of bioluminescent species inhabiting the top layers in the ocean were already described, the accessibility of deep water trawling, below 200 fathoms, revealed almost all specimens to be bioluminescent. Although infrequent among terrestrial animals, it became evident that bioluminescence was near universal in the deep. It was also apparent that the bioluminescence phenotype was widely distributed in Nature, fireflies and glowing wood on land, to completely different classes of organisms in the sea. As a result of the very active collecting activity during this time, it can be estimated that more than half of all bioluminescent species known to this day, were identified during the $19^{\text {th }}$ Century.

In the middle of the century, Heller made microscopic examination of «shining wood» and determined with certainty that fungal threads (mycelia) growing on the wood, were the origin of the luminescence. This discovery allied this bioluminescence system with the already known bioluminescence from mushrooms. $\mathrm{He}$ then established the bacterial origin of «shining flesh» and putrefying fish luminescence. $\mathrm{He}$ could wipe off some luminescence and use it to «inoculate» a dark fish. In later years, as the field of microbiology developed, the pioneers Pfluger, Beijerinck, Giard, Ludwig, and others, made many studies of bacterial bioluminescence, characterizing these bacteria and discovering the parasitic and symbiotic habitats.

Even though physical instrumentation was still too primitive for accurate spectral determination, from careful observation it was concluded that bioluminescent spectra were contributed to by separate colors. The spectra lacked the dark lines evident in the spectrum of sunlight. Similarly, only rough estimates of light intensity could be achieved «illumination enough to read by». Chemical science also was still not advanced enough to make much progress in identification of the active substances involved. Determination of chemical structures had to wait another 100 years. However, it should be noted that Dubois' findings were among the first demonstrations of an enzyme-substrate reaction, the beginnings of the subject of Biochemistry.

Bioluminescence was a very active field of research in the $19^{\text {th }}$ Century. Since that time, the development of modern technology has enabled advances in this and many other areas of Science, but it is clear that the scientific method itself, was well in place in the 1800 's. The $19^{\text {th }}$ Century was truly the beginning of «Modern Science».

This article is based on the first lecture in a course on Bioluminescence presented by the author at the Siberian Federal University, Krasnoyarsk, Russia, in September, 2008. The complete course may be freely downloaded from the internet.

\section{Origin of nomenclature}

The insect genus: Pyrophorus, from Greek pyro fire; phero to bear.

Phosphor: from Greek phos light; phosphoros the morning star.

Lucifer: «light bearing», Latin lux, lucis light; lucifer the morning Star. Luciferase and luciferin are generic terms used today. 


\section{References}

The content of this article is almost completely derived from the definitive and scholarly work of Harvey (1957). Almost all bioluminescence research published in the first half of the $20^{\text {th }}$ Century can be found described in Harvey (1952). The "Bioluminescence» section of «Photobiological Sciences Online» updates the subject to the present time.

Harvey, E.N. (1957) A history of luminescence from the earliest times until 1900. 692 pp. (American Philosophical Society, Philadelphia).

Harvey, E.N. (1952) Bioluminescence. 646 pp. (Academic Press, New York).

Needham, J., Wang, L., Robinson, K.G. (1962) Science and civilization in China, Vol. 4, Part 1 Physics, pp. 71-76 (Cambridge University Press).

Photobiological Sciences Online (2009). (Smith, K. ed.) Bioluminescence. http://www. photobiology.info.

Shapin, S., Shaffer, S. (1985) Leviathon and the air pump: Hobbes, Boyle, and the experimental life. (Princeton University Press). 